\section{Diagnostic accuracy of novel ultrasonographic halo score for giant cell arteritis: methodological issues}

We were interested to read the paper authored by Dasgupta et al published in Annals of the Rheumatic Diseases. ${ }^{1}$ In a prospective study design, 89 patients suspected of giant cell arteritis (GCA) were included. The authors used receiver operating characteristic, sensitivity, specificity and likelihood ratio (LR) for assessing the diagnostic accuracy of halo counts and halo scores and their relationship with disease severity in detecting GCA. Final clinical diagnosis after 6 months was considered as gold standard. In conclusion, they reported that both halo count and halo score can quantify the extent of vascular inflammation in GCA, and halo score has a better detecting of GCA rather than Halo count.

Although we admire this excellent study, we would like to explain some methodological issues that can cause misinterpretation. First of all, there is a difference between test research and diagnostic research. Diagnostic accuracy is focused on a test's added contribution to estimate the diagnostic probability of disease presence or absence. ${ }^{2}$ In this way, the authors need to apply several tests and measure the performance of the new test in comparison with others. However, in the current study, the authors tended to evaluate test accuracy since they did not consider other tests and hence cannot provide information about the diagnostic added value of the test. ${ }^{3}$ In fact, without the diagnostic added value, there is no evidence about the beneficial diagnostic yields of the new test. ${ }^{4}$ Another limitation relates to the interpretation of the amount of LRs. Dasgupta et al interpreted that a positive LR greater than 6.41 and 2.0 can effectively predict the GCA and temporal artery (TA) biopsy, respectively. It should be noted that the range of LR+ is one to infinity and the higher the LR+, the more accurate the test is. Actually, an LR+ equal to 2 or 6 is a clear evidence for inaccuracy of the tests. ${ }^{5}$ Also, assessing the diagnostic OR for GCA (halo count: 4.1, halo score: 5.40 ) and temporal artery biopsy (TAB) (halo count: 12.77, halo score: 9.4) confirms the inaccuracy of both tests.

Finally, for assessing diagnostic accuracy, it is important to evaluate both the discrimination and calibration of the new test. Without assessing calibration, it is not possible to compare the probability of the observed and predicted GCA and how these probabilities agree with the observed proportions of later developing disease. $^{6}$

We thus argue that there are some methodological limitations and approaches to overcome them for assessing diagnostic accuracy; otherwise, misinterpretation cannot be avoided.
Hadis Ghajari, ${ }^{1}$ Siamak Sabour $\circledast^{2}$

${ }^{1}$ Epidemiology, Shahid Beheshti University of Medical Sciences, Tehran, Iran (the Islamic Republic of)

${ }^{2}$ Clinical Epidemiology, Shahid Beheshti University of Medical Sciences, Tehran, Iran (the Islamic Republic of)

Correspondence to Professor Siamak Sabour, Clinical Epidemiology, Shahid Beheshti University of Medical Sciences, Tehran, Iran (the Islamic Republic of); s.sabour@sbmu.ac.ir

Contributors SS: writing, review and editing; methodology; and validation. HG: writing of the original draft and conceptualisation.

Funding The authors have not declared a specific grant for this research from any funding agency in the public, commercial or not-for-profit sectors.

Competing interests None declared.

Patient and public involvement Patients and/or the public were not involved in the design, conduct, reporting or dissemination plans of this research.

Patient consent for publication Not required.

Provenance and peer review Not commissioned; internally peer reviewed.

(c) Author(s) (or their employer(s)) 2020. No commercial re-use. See rights and permissions. Published by BMJ.

\section{Check for updates}

To cite Ghajari H, Sabour S. Ann Rheum Dis Epub ahead of print: [please include Day Month Year]. doi:10.1136/annrheumdis-2020-218038

Received 18 May 2020

Accepted 21 May 2020

\section{Linked}

http://dx.doi.org/10.1136/annrheumdis-2020-218144

Ann Rheum Dis 2020;0:1. doi:10.1136/annrheumdis-2020-218038

ORCID iD

Siamak Sabour http://orcid.org/0000-0002-1928-992X

\section{REFERENCES}

1 van der Geest KSM, Borg F, Kayani A, et al. Novel ultrasonographic halo score for giant cell arteritis: assessment of diagnostic accuracy and association with ocular ischaemia. Ann Rheum Dis 2020;79:393-9.

2 Grobbee DE, Hoes AW. Clinical epidemiology. Jones \& Bartlett Publishers, 2014.

3 Sabour S. A common mistake in assessing the diagnostic value of a test: failure to account for statistical and methodologic issues. J Nucl Med 2017;58:1182-3.

4 Ferrante di Ruffano L, Hyde CJ, McCaffery KJ, et al. Assessing the value of diagnostic tests: a framework for designing and evaluating trials. BMJ 2012;344:e686.

5 Šimundić A-M. Measures of diagnostic accuracy: basic definitions. EJIFCC 2009;19:203.

6 Cook NR. Statistical evaluation of prognostic versus diagnostic models: beyond the ROC curve. Clin Chem 2008;54:17-23. 